Original Article

\title{
The effects of chest expansion resistance exercise on chest expansion and maximal respiratory pressure in elderly with inspiratory muscle weakness
}

\author{
Chang-Beom Kim, PT, MS ${ }^{1)}$, Jin-Mo Yang, PT, MS ${ }^{1)}$, Jong-Duk Chol, PT, $\mathrm{PhD}^{2)^{*}}$ \\ 1) Department of Physical Therapy, Graduate School, Daejeon University, Republic of Korea \\ 2) Department of Physical Therapy, College of Natural Science, Daejeon University: 62 Daehak-ro, \\ Dong-gu, Daejeon 300-716, Republic of Korea
}

\begin{abstract}
Purpose] The aim of this study was to examine the effect of chest expansion resistance exercises (CERE) on chest expansion, maximal inspiratory pressure (MIP), and maximal expiratory pressure (MEP) in elderly people with inspiratory muscle weakness. [Subjects] Thirty elderly people with inspiratory muscle weakness (MIP $<80 \%$ of the predicted value) were randomly and equally assigned to a chest expansion resistance exercise (CERE) group, core conditioning exercise (CCE) group, and control group. [Methods] The intervention was applied to the CERE group and CCE group five times per week, 30 minutes each time, for six weeks. A tapeline was used to measure upper and lower chest expansion. MIP and MEP before and after the intervention were measured and compared. [Results] There was significant improvement in upper and lower chest expansion and MIP after the intervention in both the CERE group and the CCE group, whereas the control group did not show any significant difference. MEP did not significantly change in any of the three groups after the intervention. [Conclusion] The CERE group underwent greater changes than the CCE group, which proves that the CERE is more effective for improving elderly people's chest expansion capacity and MIP in elderly people. Therefore, application of the CERE by therapists is recommended if the environment and conditions are appropriate for enhancement of chest expansion capacity and MIP in elderly people.

Key words: Elderly, Respiration, PNF
\end{abstract}

(This article was submitted Oct. 21, 2014, and was accepted Dec. 11, 2014)

\section{INTRODUCTION}

Average life expectancy increased dramatically from 50 years old in the early 1900 s to 80 years old in $2008^{1)}$. However, in line with increased life expectancy, as humans age, their lung elasticity, diaphragm movement, and chest expansion decrease, and their respiratory muscles weaken. This frequently gives rise to problems with respiratory function $^{2)}$. Physical therapeutic approaches for the thorax include thoracic mobilization, stretching of the respiratory muscles, and strengthening of the respiratory muscles. Such respiratory rehabilitation reduces respiratory problems in patients with respiratory dysfunction ${ }^{3)}$. In addition, elderly people can improve and maintain their cardiopulmonary circulation and also increase their oxygen intake through continuous physical training ${ }^{4}$. In a society where aging is becoming a longer process due to increased average life expectancy, research on interventions to improve respiratory function

*Corresponding author. Jong-Duk Choi (E-mail: choidew@ dju.kr)

C2015 The Society of Physical Therapy Science. Published by IPEC Inc. This is an open-access article distributed under the terms of the Creative Commons Attribution Non-Commercial No Derivatives (by-ncnd) License $<$ http://creativecommons.org/licenses/by-nc-nd/3.0/> . in the elderly should be actively conducted. A recent study showed that PNF respiration exercise is effective in increasing the pulmonary function of normal adults ${ }^{5}$. However, there has been insufficient research in this area up to now. Accordingly, the aim of this study was to examine the effect of chest expansion exercises on chest expansion, maximal inspiratory pressure (MIP), and maximal expiratory pressure (MEP) in elderly people whose respiratory function has declined and to subsequently present an intervention method aimed at improving their respiratory function.

\section{SUBJECTS AND METHODS}

This study was conducted in a nursing home located in Yongin City, Republic of Korea, from May 10 to July 13, 2014 , and the average age of the participants was 66 years old (Table 1). All of the protocols used in this study were approved by the University of Daejeon. Before participation, the procedures, risks, and benefits were explained to all the participants, who gave their informed consent. The participants' rights were protected according to the guidelines of the University of Daejeon. The subjects were all aged 60 or older, had inspiratory muscle weakness (MIP $<80 \%$ of the predicted value), and showed no pulmonary disease in a radiological test and physical chest examination. Thirty subjects were randomly and equally assigned to a chest expan- 
Table 1. General characteristics of subjects $(n=30)$

\begin{tabular}{lccc}
\hline & $\begin{array}{c}\text { CERE group } \\
(\mathrm{N}=10)\end{array}$ & $\begin{array}{c}\text { CCE group } \\
(\mathrm{N}=10)\end{array}$ & $\begin{array}{c}\text { Control group } \\
(\mathrm{N}=10)\end{array}$ \\
\hline Gender (male/female) & $6 / 4$ & $6 / 4$ & $5 / 5$ \\
Age $(\mathrm{yrs})$ & $66.7 \pm 5.1^{\mathrm{a}}$ & $66.8 \pm 4.3$ & $64.4 \pm 2.8$ \\
Height $(\mathrm{cm})$ & $163.9 \pm 5.0$ & $165.1 \pm 6.5$ & $164.7 \pm 4.6$ \\
Weight $(\mathrm{kg})$ & $66.5 \pm 3.8$ & $65.3 \pm 5.7$ & $64.6 \pm 5.0$ \\
BMI & $24.7 \pm 1.9$ & $24.3 \pm 2.8$ & $24.1 \pm 2.5$ \\
Tobacco abuse & $40 \%$ & $40 \%$ & $50 \%$ \\
\hline aMean \pm SD. CERE: chest expansion resistance exercise; CCE: core conditioning exercises; \\
BMI: body mass index
\end{tabular}

sion resistance exercise (CERE) group, core conditioning exercise (CCE) group, and control group.

The CERE is an exercise based on a proprioceptive neuromuscular facilitation breathing exercise. A therapist palpated the anterior and posterior aspects of a side-lying subject with the thoracic apex as the standard as if embracing the aspects on both sides. From the time the patient started inspiration after expiration, the therapist provided resistance toward the coccygeal vertebrae from the palpated areas. Resistance was applied to the maximum extent possible without impeding the patient's inspiration. Just before the patient exhaled, the therapist gave the oral command, "Please breathe out slowly", and applied continuous resistance, thereby allowing the patient to perform an active respiration exercise ${ }^{6}$. One set of exercises was composed of 15 repetitions, and the subjects conducted 10 sets of exercises in total. A rest period of 30 seconds was allowed after the warm-up exercise, the cooldown exercise, and each set of the main exercise. For the CCE, a trunk muscle relaxation design was used in combination with a stretch pole. All of the "seven basic" exercises listed below were conducted in a lying position on a stretch pole. The subjects were instructed to perform all these exercises, with an alarm set for three minutes per exercise using a stopwatch. The subjects were allowed to take a rest of about one minute after each exercise, and the whole session continued for approximately 30 minutes. The "seven basic" exercises were performed as follows: 1) Draw a small circle on the floor using a hand. 2) With both arms stretched upwards in parallel, induce abduction of the scapular and relax the adductor. 3) As if slipping on the floor, conduct shoulder abduction and adduction. 4) With the knees slightly flexed and the hips extended, externally and internally rotate the hips. 5) With the knees slightly flexed and the hips externally rotated, abduct the hips. 6) Slide both sides of the back on the stretch pole. 7) Breathe abdominally, which causes the abdomen to move during inspiration and expiration ${ }^{3)}$. The intervention was applied to each group five times per week, 30 minutes per each time, for six weeks.

A tapeline was used to measure chest excursion, and all measurements were taken with the patients adopting a straight posture while standing. Regarding chest expansion, the axillary level was evaluated for upper thorax assessment, and the xyphoid level was evaluated for lower thorax assessment. For the upper thorax, the third intercostal space at the midclavicular line and the fifth thoracic spinous process were marked with a measuring pen. The tapeline was placed parallel to the ground, and the degree of expansion was measured during inspiration. For the lower thorax level, the tenth thoracic vertebra's spinous process and xiphoid process were marked with a measuring pen. The tapeline was placed on the ground parallel to the two marked points, and the expansion speed was measured during both inspiration and expiration ${ }^{7}$. MicroRPM (Micro Medical Ltd., UK) was used to measure MIP and MEP. The measurements were taken while the patients were sitting up straight. During inspiration, the mouth piece was adhered to the mouth as tightly as possible, and loss of pressure was reduced to a minimum using a nose grip. All measurements were taken using a blind examiner, and the average values from three sets of measurements were used for statistical analysis.

The data collected in this study were statistically processed using PASW Statistics Version 18.0. The subjects' general characteristics were expressed as averages and standard deviations using descriptive statistics. A paired ttest was conducted in order to facilitate the examination of differences before and after the intervention after deriving each group's averages and standard deviations. In order to verify the differences between the three groups' average values, one-way analysis of variance was used, in addition to a Scheffe post hoc test. Statistical significance was set at 0.05 .

\section{RESULTS}

There was significant improvement in upper and lower chest expansion after the intervention in both the CERE group and the CCE group, but there was no significant improvement in upper and lower chest expansion in the control group. According to the post hoc test results, upper chest expansion significantly improved in the CERE group and the CCE group compared with the control group, and lower chest expansion significantly improved in the CERE group relative to the control group. However, there was no significant improvement in the CCE group compared with the control group. According to the results of a comparison between MIP differences before and after the intervention, the CERE group and the CCE group showed significant differences in MIP after the intervention compared with before it, but the control group showed no significant differences. According to the post hoc test results, the CCE group and the CERE group showed significant changes compared with 
Table 2. A comparison of upper chest expansion, lower chest expansion, MIP, and MEP $(\mathrm{n}=30)$

\begin{tabular}{|c|c|c|c|}
\hline & $\mathrm{n}$ & Before & After \\
\hline \multicolumn{4}{|c|}{ Upper chest expansion (cm) } \\
\hline CERE group & 10 & $2.9 \pm 1.1$ & $4.3 \pm 1.0^{* \dagger}$ \\
\hline CCE group & 10 & $3.2 \pm 1.2$ & $4.4 \pm 1.0^{* \dagger}$ \\
\hline Control group & 10 & $3.0 \pm 1.0$ & $3.3 \pm 0.9$ \\
\hline \multicolumn{4}{|c|}{ Lower chest expansion (cm) } \\
\hline CERE group & 10 & $2.5 \pm 0.7$ & $4.2 \pm 0.7^{* \dagger}$ \\
\hline CCE group & 10 & $2.7 \pm 0.9$ & $3.9 \pm 0.7^{*}$ \\
\hline Control group & 10 & $2.9 \pm 0.7$ & $3.2 \pm 0.7$ \\
\hline \multicolumn{4}{|l|}{$\operatorname{MIP}\left(\mathrm{cmH}_{2} 0\right)$} \\
\hline CERE group & 10 & $54.1 \pm 3.6$ & $72.3 \pm 7.6^{*}+$ \\
\hline CCE group & 10 & $54.2 \pm 3.8$ & $61.0 \pm 8.2^{* \dagger}$ \\
\hline Control group & 10 & $54.8 \pm 3.4$ & $53.3 \pm 5.1$ \\
\hline \multicolumn{4}{|l|}{$\mathrm{MEP}\left(\mathrm{cmH}_{2} 0\right)$} \\
\hline CERE group & 10 & $65.0 \pm 5.2$ & $65.8 \pm 6.5$ \\
\hline CCE group & 10 & $66.0 \pm 4.9$ & $65.6 \pm 5.6$ \\
\hline Control group & 10 & $65.4 \pm 5.5$ & $64.0 \pm 5.1$ \\
\hline
\end{tabular}

${ }^{a}$ Mean \pm SD. ${ }^{*} \mathrm{p}<0.05$. ${ }^{\dagger}$ Significantly improved compared with control group. ${ }^{+}$Significantly improved compared with CCE group. CERE: chest expansion resistance exercise; CCE: core conditioning exercises; MIP: maximal inspiratory pressure; MEP: maximal expiratory pressure

the control group, and there was a more significant increase in the CERE group relative to the CCE group. MEP did not significantly change in any of the three groups after the intervention (Table 2).

\section{DISCUSSION}

Duration of gait exercise on a treadmill decreases by about $10 \%$ every 10 years. By the time an individual reaches 60 years of age, his/her physical exercise ability has decreased by $41 \%$, and his/her maximum oxygen intake has decreased by about $5.5 \%$ per decade ${ }^{8}$. As aging progresses, respiratory function decreases, together with a reduction in physical exercise ability. Further research is required on interventions to enhance respiratory function in elderly individuals. Accordingly, this study aimed to examine the effects of the CERE and the CCE when used to enhance the respiratory function of elderly people with declining capacity in terms of chest expansion and MIP.

Muscle tension of the rib cage and mechanical properties caused by movement of the rib cage are important factors in air flow during inspiration and expiration. In addition, the thorax has an elastic structure that expands and contracts during breathing, and interaction between the lung and the chest cavity is a crucial parameter representing the gas exchange ability of the lung ${ }^{9}$. Further, the expansion and contraction of the lungs are affected by the capacity of the thorax, which is determined by the mobility of the skeletal muscles, the elasticity of surrounding soft tissues, and the intensity of the respiratory muscles ${ }^{10)}$. Research results have shown that tidal volume is more affected by movement of the rib cage than abdominal motion ${ }^{11)}$. Therefore, the degree of chest expansion is considered to be closely related to respiratory function and an important element in representing respiratory function.

This study evaluated upper and lower chest expansion. According to the experimental results, the control group did not experience significant changes in upper chest expansion after the intervention, while the CERE group and the CCE group did, with similar results in the two groups. However, in the lower chest expansion test, the CCE group showed significant improvement, but this improvement was not significant relative to the control group. Conversely, the CERE group showed significant improvement after the intervention compared with the control group. This result is noteworthy because the CERE is an intervention that uses a therapist's resistance, while the CCE is an intervention based on stretching. The results indicate that the CCE group showed significant improvement compared with the control group in upper chest expansion but did not show significant improvement relative to the control group in lower chest expansion. This is similar to the results of a study that examined the effects of the CCE on chest expansion in healthy elderly people. The fact that the CERE group's improvement was greater than the CCE group's improvement is supported by the findings indicating that respiratory muscle strength should be increased to improve respiratory function and that resistance exercise is important ${ }^{12)}$.

MIP and MEP are used when evaluating respiratory muscle function in the clinical field because they show changes in the volume of each muscle and the respiratory system ${ }^{13)}$. In addition, the association between the respiratory system and pressure-volume is based on the fact that achievement of a higher maximum inspiratory pressure is determined by inspiration at the lowest residual volume; therefore, strong respiratory muscles create a higher pulmonary volume ${ }^{14)}$.

MIP significantly improved when the CERE and the CCE were compared before and after the intervention, and both groups showed significant changes compared with the control group. According to the post hoc test results, the CERE group's changes were statistically significant relative to those of the CCE group. Although the subjects were different, a similar study was conducted in which chest wall expansion exercises were applied to patients with chronic obstructive lung disease, and an outcome of significant improvement in pulmonary functions, dyspnea, and thorax expansion degree was obtained. That study is considered to support the present study results ${ }^{15)}$

In this study, the CCE's upper chest expansion and MIP significantly improved compared with those of the control group. The present study results are the same as those of a study in which exercises to stretch the respiratory muscles enhanced chest expansion capabilities and pulmonary function $^{16)}$. However, in all evaluations, the CERE group underwent greater changes than the $\mathrm{CCE}$ group, which proves that the CERE is more effective for improving chest expansion capacity and pulmonary function in elderly people. A major limitation of this study is that it utilized a comparatively small sample size.

In conclusion, application of the CERE by a therapist is recommended if the environment and conditions are appropriate for enhancement of chest expansion capacity and 
respiratory function in elderly people. However, if they are not, the CCE program is also considered to be effective for improving these issues in elderly people.

\section{REFERENCES}

1) Roger VL, Go AS, Lloyd-Jones DM, et al.: Heart disease and stroke statistics-2013 update. A report from the American Heart Association. Circulation, 2012, 125: 2-220. [CrossRef]

2) McClaran SR, Babcock MA, Pegelow DF, et al.: Longitudinal effects of aging on lung function at rest and exercise in healthy active fit elderly adults. J Appl Physiol 1985, 1995, 78: 1957-1968. [Medline]

3) Yokoyama S, Gamada K, Sugino S, et al.: The effect of "the core conditioning exercises" using the stretch pole on thoracic expansion difference in healthy middle-aged and elderly persons. J Bodyw Mov Ther, 2012, 16: 326-329. [Medline] [CrossRef]

4) Kohrt WM, Malley MT, Coggan AR, et al.: Effects of gender, age, and fitness level on response of VO2max to training in 60-71 yr olds. J App Physiol 1985, 1991, 71: 2004-2011. [Medline]

5) Seo K, Cho M: The effects on the pulmonary function of normal adults proprioceptive neuromuscular facilitation respiration pattern exercise. J Phys Ther Sci, 2014, 26: 1579-1582. [Medline] [CrossRef]

6) Adler SS, Beckers B, Buck M: PNF in Practice: An Illustrated Guide, 4th ed. Berlin: Springer-Verlag, 2014

7) Bockenhauer SE, Chen H, Julliard KN, et al.: Measuring thoracic excursion: reliability of the cloth tape measure technique. J Am Osteopath Assoc, 2007, 107: 191-196. [Medline]

8) Dehn MM, Bruce RA: Longitudinal variations in maximal oxygen intake with age and activity. J Appl Physiol, 1972, 33: 805-807. [Medline]

9) Mirtz TA: Acute respiratory distress syndrome: clinical recognition and preventive management in chiropractic acute care practice. J Manipulative Physiol Ther, 2001, 24: 467-473. [Medline] [CrossRef]

10) Fishman RS, Systrom DM: Preoperative cardiopulmonary exercise testing: determining the limit to exercise and predicting outcome after thoracotomy. J Cardiothorac Vasc Anesth, 1991, 5: 614-626. [Medline] [CrossRef]

11) Akira T, Arisa K, Yoshimi M, et al.: Analysis of Thoracoabdominal motion during incremental work cycle exercise. J Phys Ther Sci, 2000, 12: 131-135. [CrossRef]

12) Kido $S$, Nakajima $Y$, Miyasaka $T$, et al.: Effects of combined training with breathing resistance and sustained physical exertion to improve endurance capacity and respiratory muscle function in healthy young adults. J Phys Ther Sci, 2013, 25: 605-610. [Medline] [CrossRef]

13) Gibson GJ: Lung volumes and elasticity. In: Hughes JM, Pride NB, editors Lung function tests: physiological principles and clinical applications. Michigan: Saunders, 1999, pp 45-56.

14) George RB, Light RW, Matthay MA, et al.: Chest medicine: essential of pulmonary and critical care medicine, 5th ed. New York: Lippincott Williams \& Wilkins, 2005.

15) Leelarungrayub D, Pothongsunun P, Yankai A, et al.: Acute clinical benefits of chest wall-stretching exercise on expired tidal volume, dyspnea and chest expansion in a patient with chronic obstructive pulmonary disease: a single case study. J Bodyw Mov Ther, 2009, 13: 338-343. [Medline] [CrossRef]

16) Izumizaki M, Kakizaki $F$, Tanaka $K$, et al.: Immediate effects of thixotropy conditioning of inspiratory muscles on chest-wall volume in chronic obstructive pulmonary disease. Respir Care, 2006, 51: 750-757. [Medline] 